\title{
A digital photographic method for 3D reconstruction of standing tree shape
}

\author{
Adrian Ilie HAPCA ${ }^{\mathrm{a} *}$, Frédéric MoTHE ${ }^{\mathrm{b}}$, Jean-Michel LEBAN ${ }^{\mathrm{b}}$ \\ ${ }^{a}$ Centre for Timber Engineering, Napier University, Merchiston Campus, Edinburgh, EH10 5DT, Scotland \\ ${ }^{\mathrm{b}}$ INRA - Centre de Recherches de Nancy, Laboratoire d'Étude des Ressources Forêt-Bois, 54280 Champenoux, France
}

(Received 15 June 2006; accepted 15 February 2007)

\begin{abstract}
A digital photographic method is presented which is able to reconstruct the profile of the stem on standing trees up to a height of $12 \mathrm{~m}$ and to provide a fine level of detail. The method uses two digital photographs taken at $90^{\circ}$ to each other and does not require special illumination conditions. A method is proposed to perform the data acquisition process from the two photographs and to transform the stem dimensions and 3-D position from pixels to units of length. The accuracy of this method for measuring tree shape was tested by comparing the results with those obtained from a laser system. The comparison showed that the photographic method provides a good assessment of standing tree shape.
\end{abstract}

3D profile / standing trees / digital camera / photogrammetry / Picea abies

Résumé - Mesure de la forme des arbres sur pied par photogrammétrie. La méthode photographique présentée dans cet article permet la reconstruction en 3D du profil du tronc d'arbres sur pied jusqu'à une hauteur de $12 \mathrm{~m}$. On utilise un appareil photo numérique pour faire deux prises de vue orientées à $90^{\circ}$ l'une de l'autre. Il n'y a pas de contrainte particulière d'éclairage. Le traitement des images conduit à la représentation tridimensionnelle des tiges et à la mesure des indicateurs de forme. La précision de la méthode proposée est évaluée par référence à des mesures réalisées avec un théodolite à visée laser. Les résultats montrent que la méthode photographique permet des mesures précises de la forme des arbres.

profil 3D / arbre sur pied / photo numérique / photogrammétrie / Picea abies

\section{INTRODUCTION}

The commercial value of logs for processing into solid wood is mainly determined by the size and straightness of the tree stem, and the number and size of branches. One of the first steps required when converting trees to sawmill products is a description of the quality of the raw material. According to Lundgren [9], the geometry of a stem is a good indicator of $\log$ quality. As a result, a variety of different non-contact approaches have been developed during the last century to collect data on the stem characteristics of standing trees (e.g., tree heights, upper stem diameters, stem straightness, form of stem sections, crown projection, etc.). These approaches can be divided into two broad categories (i) approaches for measuring the tree dendrometric characteristics and (ii) approaches for measuring the tree straightness. In both situations photographic techniques were generally employed, since they are convenient for indirectly estimating the shape of the trees.

One of the pioneers in forestry photogrammetry was Weber [15]. In 1902, he used a camera orientated parallel to the stem axis to obtain tree dendrometric characteristics using a conversion scale into the plane of the photograph. This principle was used and improved later by Prodan [11], Crosby et al. [4], Nosenzo [10] and Gaffrey et al. [6]. Recent developments in

*Corresponding author: a.hapca@napier.ac.uk this area are characterised by the application of digital photography $[1,2,5,8]$, whereby photographs are recorded directly in digital format.

The approach of using photogrammetry to analyse the straightness of standing trees was first proposed in the 1960s by Shelbourne and Namkoong [13]. The principle was to take photographs of a tree from two perpendicular directions. These images represent the projection of the tree profile onto the plane of the photographs. The straightness of the stem is then expressed by the angle of lean and sums of squared deviation to different axes. Two series of tests, one on a wire helix and the other on eight 11-year-old plantation trees, were carried out to estimate the angle of lean. Results showed that the method is characterised by a high level of repeatability. However, with this method data are recorded from the photographs using projections onto a screen which is time consuming and can result in errors.

The methodology proposed by Shelbourne and Namkoong [13] was improved by Thomas [14] who proposed using a 35$\mathrm{mm}$ camera and two flashes to provide better contrast in the photographs. The author notes that the $35-\mathrm{mm}$ camera used gives the smallest distortion of the objects on the picture. The photographic film is scanned and the assessment of the threedimensional (3D) shape of standing tress is done using a semiautomatic imaging analysis procedure. To test the method, three sets of photographs were taken. The results obtained 
showed that the standard error for the diameter measurement was up to $30 \mathrm{~mm}$.

Other methods have been used to measure the shape of standing trees. Radi and Castera [12] estimated the 3D position of the average profile of the stem by direct contact measurements at different heights using a plumb line, while Constant et al. [3] proposed a method which used laser systems (theodolite method). In this method, a series of targets is attached to a standing tree and the coordinates of these targets are measured using a theodolite. The tree is then felled, cut into logs and the external shape of each log measured in the laboratory. This information is then combined and used to reconstruct the initial 3D shape of the tree. The accuracy of this approach was quantified by taking two measurements of the coordinates of a series of targets attached to nine mature standing trees, without moving the total station. The results from the comparison indicated a good level of precision for the first $12 \mathrm{~m}$ of the stem (interval of uncertainty $\pm 7.2 \mathrm{~mm}$ ) and lower for heights above $12 \mathrm{~m}$ (interval of uncertainty $\pm 20.8 \mathrm{~mm}$ ). According to these authors, wind was the most limiting factor to measure the position of the standing trees. The disadvantages of this method are that a minimum of three targets per log must be attached to the stem of standing trees, and considerable time is required for the laboratory measurements (up to $4 \mathrm{~h}$ for one 2 -m-long $\log$ ) in addition to the field work. Furthermore, it is a destructive method and therefore is not suitable for forest inventories.

While the theodolite method has been shown to have a high degree of precision and repeatability, it is unlikely to be used in an operational context as studies on large numbers of trees require faster and less expensive methods. With the development of charged coupled devices (CCD), digital camera technology has become a relatively simple and efficient approach to take photographs of standing trees. The primary advantage of this technique is related to the fact that digital photograph manipulation allows more operations to be carried out than could be accomplished with standard film technology, such as the analysis of histograms of colours. The aim of this paper is twofold, firstly to show how the features in digital photographs can be used to measure the 3D profile of a standing tree, and secondly to test the repeatability of this method. Validation of this method was achieved by comparing the standing tree profile obtained by the photographic method with the profile measured by the theodolite. The measurements were repeated twice on two sets of photographs by two different operators. Additional validation of the approach involved comparing estimates of stem slope in the first $4 \mathrm{~m}$ and stem diameters obtained by the photographic method with those obtained from direct measurements.

\section{MATERIAL AND METHODS}

\subsection{Principle of the photographic method}

The projection of a vertical flat object onto a parallel plane is given by a homothety (i.e., a similarity transformation) with a scale factor $\mu$ given by:

$$
\mu=\mathrm{f} / \mathrm{D}
$$

where for a camera, $\mathrm{f}$ is the focal distance and $\mathrm{D}$ is the horizontal distance from the focus to the object.

In the case when the focal distance is not known, the scale factor $\mu$ may be estimated by measuring the projected length $l$ of a calibration sample of length $\mathrm{L}$ placed in the object's plane:

$$
\mu=l / \mathrm{L}
$$

where, $l$ is the length of the projection, and $\mathrm{L}$ is the real length.

In reality, a tree is not a flat object and the scale factor may vary with the distance to the focus for each point on a tree. Nevertheless, the error can be reduced by placing the camera far enough from the tree ( $\mathrm{D}$ is approximately $18.5 \mathrm{~m}$ in this study). Furthermore, the image deformations due to the camera optics and the digitalization device are much more complex than a simple homothetic transform.

Assuming that these transformations do not include any rotation or shearing, we only have to consider the local variations of the scaling factors in the horizontal and vertical directions. The ratio between the scaling factors measured at two different points in the same image does not depend on the target object, nor on the distance from the object to the camera. It results from the previous hypothesis that the field of variation of the relative scaling factors may be considered as an acquisition system property, independent of the actual image.

To express the distortion we consider two relative scaling factors $F H$ (horizontal) and $F V$ (vertical), defined at a given point within the image as:

$$
\begin{aligned}
& F H=\mu H / \mu 0 H \\
& F V=\mu V / \mu 0 V
\end{aligned}
$$

where, $\mu H$ and $\mu V$ are the horizontal and vertical scaling factors, respectively, and $\mu 0 \mathrm{H}$ and $\mu 0 \mathrm{~V}$ are the scaling factors at the centre of the image.

We used a digital photograph of scaled paper to develop a regression model which allowed us to estimate the relative scaling factors at any location in the vertical direction of any photograph taken using the same camera settings. The horizontal distortion $(F H)$ was estimated using a second regression model involving the vertical relative scaling factor $(F V)$. This method makes use of a vertical calibration sample placed in the same plane as the target tree for calibration. By following the procedure described above, the scaling factors in the horizontal and vertical directions for the digital photograph were calculated for each point and expressed in millimetres/pixel. The dimension and the position on the picture of the tree projection can then be transformed from pixels into millimetres.

Since one photograph of the tree represents its projection in a vertical plane, the 3D profile of the tree can be obtained from two photographic images taken from two perpendicular directions (Fig. 1). In this case, each photograph can be considered as representing the $Z X$ and $Z Y$ planes in a cartesian coordinate system, where the $Z$-direction corresponds to the height of the tree, and the $X$-and $Y$-directions correspond to the transverse section of the tree.

The diameters of the stem and the coordinates of the cross section centre at height $Z$ (Fig. 2) were calculated according to the formulae:

$$
\begin{aligned}
D x & =X r-X l \\
D y & =Y r-Y l \\
X & =(X l+X r) / 2 \\
Y & =(Y l+Y r) / 2
\end{aligned}
$$

where, $D x, D y$ are the stem diameters in $\mathrm{ZX}$ and $\mathrm{ZY}$ planes, respectively, $\mathrm{X}$ and $Y$ are the coordinates of the cross-section centre, $\mathrm{Xl}, \mathrm{Xr}$ 


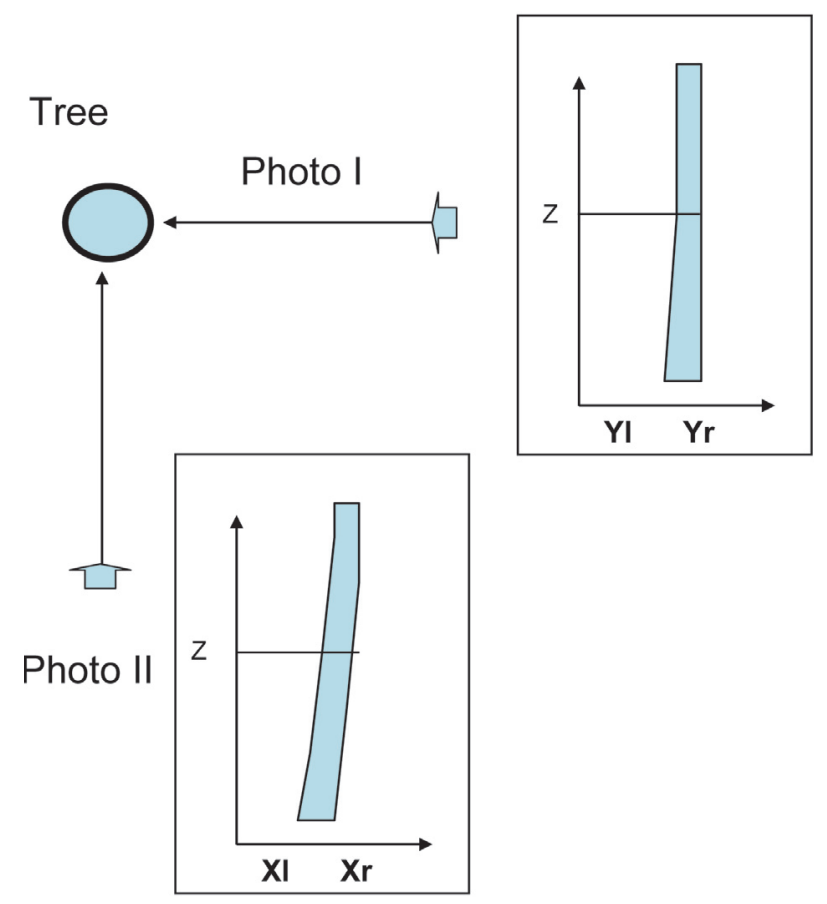

Figure 1. Overview of methodology to measure the profile of a tree using two photographs, taken from two perpendicular directions.
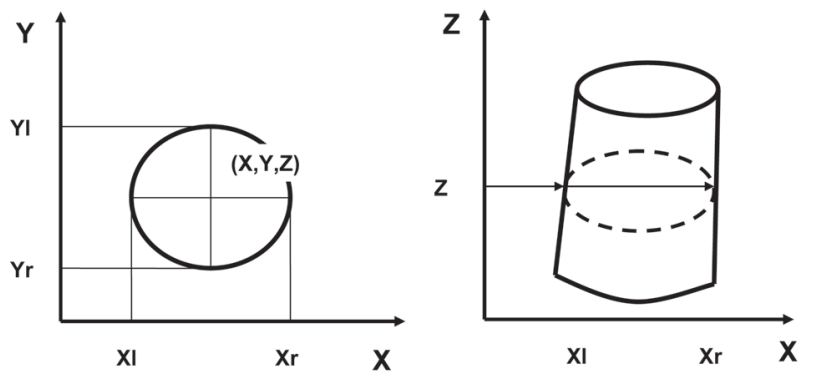

Figure 2. Schematic representation of the measurements taken in order to record the profile of the stem in the $\mathrm{XZ}$ plane, and estimation of the cross section coordinates at the height $\mathrm{Z}$.

are the coordinates of the left and right hand edges of the stem crosssection measured on photo 1 , and $Y l, Y r$ are the coordinates of left and right hand edges measured on photo 2 .

Using the 3D profile, the stem was characterised by two parameters: local slope $(\varepsilon)$, related to the axis Z, and local slope orientation $(\beta)$, related to the XY plane (Fig. 3). Both parameters were measured for the section of stem linking two cross-sections at heights 1 and 2. The local slope of the tree $(\varepsilon)$ was defined as the angle between the vertical axis and the axis linking the centre of the crosssections, while the local slope orientation $(\beta)$ is the azimuth of the leaning direction. These parameters were calculated using the following equations:

$$
\begin{aligned}
& \varepsilon=\arctan \left(\frac{\sqrt{(X 2-X 1)^{2}+(Y 2-Y 1)^{2}}}{Z 2-Z 1}\right) \\
& \beta=\arctan \left(\frac{X 2-X 1}{Y 2-Y 1}\right)
\end{aligned}
$$

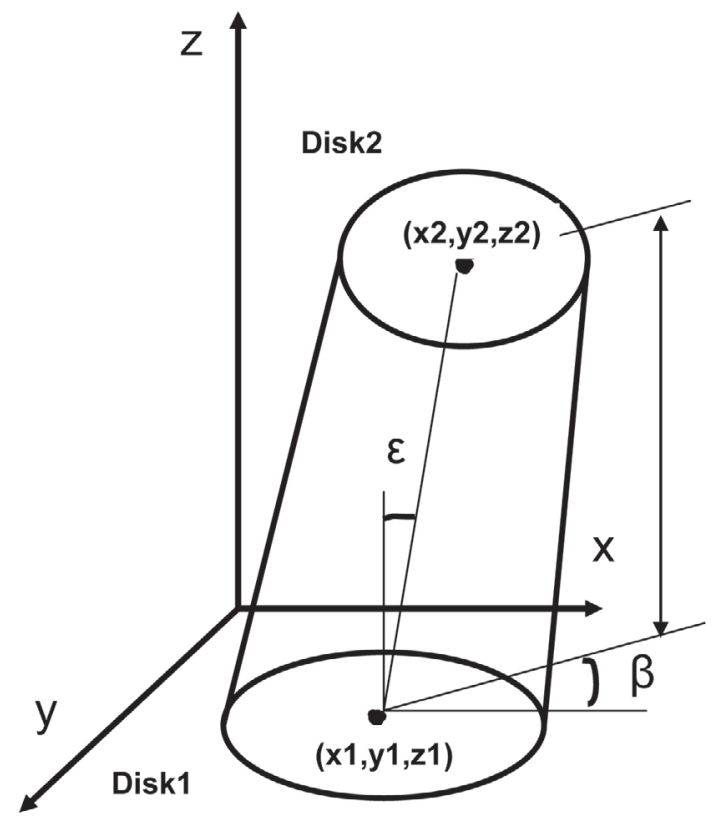

Figure 3. Calculation of the local slope $(\varepsilon)$ and local slope orientation $(\beta)$ of the stem at the height $\mathrm{Zn}$.

where: $(X 1, Y 1, Z 1)$ and $(X 2, Y 2, Z 2)$ are coordinates of the centre of cross-sections at heights 1 and 2 , respectively.

\subsection{Application of the method to measure 3D stem profiles}

Reconstruction of the 3D stem profile of trees was undertaken through a series of field and laboratory measurements. In the field, a digital camera (model Dsc-F505V, SONY Corporation, Japan) was mounted on a tripod and a spirit level used to ensure that the camera was orientated in a vertical direction. A plumb line attached to the tree was used to indicate the vertical position in the photographs and a stick of standard length $(1 \mathrm{~m})$ was used to calibrate the image. The horizontal distance between the camera and the tree was approximately $18.5 \mathrm{~m}$. Two images were taken for a particular tree and a compass was used to ensure that they were perpendicular to each other. A necessary condition for this method is to find two perpendicular directions from where the tree is visible.

Standard image editing software (Corel Photo-Paint, Corel Corporation, Ontario, Canada) was used to assess the position of the stem and its diameter (expressed in pixels) on each image. The measurement procedure requires manually recording points located on the edge of the stem. A macro was written in Excel (Microsoft Corporation, Washington, USA) to acquire the data from the two digital photographs and to convert the stem dimensions and 3D position from pixels into millimetres. The measurements on the pictures and data analysis give the 3D profile of the stem coordinates, mean stem diameter for different heights, local slope and orientation of the local slope.

\subsection{Validation of the method}

The photographic method was validated against two independent datasets. The first dataset contained a single tree which was measured 
Table I. Characteristics of the four Norway spruce stands assessed in the Vosges Mountains, France.

\begin{tabular}{|c|c|c|c|c|}
\hline & \multicolumn{4}{|c|}{ Stand } \\
\hline & Etival 2 & Etival 1 & Le Syndicat & Ferdrupt \\
\hline Age (years) & 44 & 44 & 48 & 40 \\
\hline Density (stems / ha) & 810 & 1090 & 915 & 1315 \\
\hline Dominant height $(\mathrm{m})$ & 28.9 & 27.2 & 27.4 & 25.7 \\
\hline Dominant diameter $(\mathrm{mm})$ & 371 & 356 & 409 & 352 \\
\hline Mean diameter $(\mathrm{mm})$ & 269 & 240 & 300 & 228 \\
\hline Longitude & $6^{\circ} 51^{\prime} 56^{\prime \prime}$ & $6^{\circ} 51^{\prime} 37^{\prime \prime}$ & $6^{\circ} 41^{\prime} 39^{\prime \prime}$ & $6^{\circ} 42^{\prime} 50^{\prime \prime}$ \\
\hline Latitude & $48^{\circ} 22^{\prime} 58^{\prime \prime}$ & $48^{\circ} 23^{\prime} 21^{\prime \prime}$ & $48^{\circ} 02^{\prime} 41^{\prime \prime}$ & $47^{\circ} 53^{\prime} 17^{\prime}$ \\
\hline Altitude (m) & 290 & 305 & 610 & 660 \\
\hline Ground slope $\left(^{\circ}\right)$ & 0.5 & 11 & 16 & 20 \\
\hline$(\min \rightarrow \max )$ & $(0 \rightarrow 1)$ & $(3 \rightarrow 18)$ & $(9 \rightarrow 20)$ & $(15 \rightarrow 25)$ \\
\hline Number of trees assessed & 18 & 18 & 18 & 17 \\
\hline
\end{tabular}

using a theodolite [3]. This tree was a leaning 70-year-old Norway spruce (Picea abies (L.) Karst.), with a total height of $21.5 \mathrm{~m}$ and a breast height diameter of $290 \mathrm{~mm}$. The bottom $10 \mathrm{~m}$ section of the stem was measured using both the photographic and laser methods. Two sets of photographs were taken by two different operators.

The second dataset contained 71 trees from four Norway spruce stands located in the Vosges Mountains in the north-east of France. Trees in these stands were between 40 and 48 years old and mean diameter at breast height ranged from 228 to $300 \mathrm{~mm}$. Dominant height (i.e., height of the largest tree in the stand by diameter) ranged from 25.7 up to $28.9 \mathrm{~m}$ (Tab. I). These stands were measured as part of the EU Compression Wood Project [7].

Two photographs were taken of each tree at $90^{\circ}$ to each other and the slope of the first $4 \mathrm{~m}$ of the stem was measured using a plumb line. Stem diameters were measured on the first $12 \mathrm{~m}$ using the photographic method. Each tree was then felled and stem diameters were measured at different heights using a caliper according to the project protocol. Results obtained from the photographic method were compared with those obtained from direct measurements.

\section{RESULTS AND DISCUSSION}

For the experimental settings used in this study (i.e., an average distance from the camera to the tree of $18.5 \mathrm{~m}$, 3 megapixel camera resolution and picture distortion) the largest value of the scaling factors on the pictures was $9 \mathrm{~mm} /$ pixel. This value can be considered as the resolution of the photographic method, i.e., the maximum level of detail that can be measured.

The reconstructed 3D profile of the 70-year-old Norway spruce tree in the ZX and ZY planes, together with the two photographic images is shown in Figure 4. The representation of tree shape was created using visualisation software (Bil3D) developed by INRA, using the coordinates of the centre and diameter of each cross section. This tree was characterised by a large amount of basal curvature (Fig. 5). The magnitude of lean of the stem changed gradually from the bottom to the top, and at the same time the direction of lean rotated in a counter-clock wise direction. The tree profiles in ZX and ZY planes obtained by photographic method and the theodolite are shown in Figure 6. Differences between the 3D profiles of the tree measured by the theodolite and the eight profiles measured by the photographic method using the two perpendicular photographs, and repeated twice by two operators, were calculated. There was a general trend of an increasing difference between the two methods with increasing height up the stem (Fig. 7). The maximum deviation between the two methods was approximately $100 \mathrm{~mm}$ which occurred at both 6 and $10 \mathrm{~m}$ height. The observed difference between the two methods with increasing height may in part be due to the decreasing precision of the theodolite with increasing height, as reported by Constant et al. [3]. However, it is not possible to conclusively say which method is more accurate as neither has been compared to the actual profile of the tree.

The variation between operators and between measurements was comparatively small compared with the difference between this method and the theodolite. The maximum deviation of any of the eight profiles from the average profile did not exceed $6.5 \mathrm{~mm}$ (Fig. 7). Some of this variation may be due to operator decisions about the location of the edge of the stem when the contrast in the photographs is low or when a branch obstructs the vision at the measured height.

The analysis of the second set of validation data showed a strong correlation $\left(R^{2}=0.91\right)$ between the photographic and direct measurements of the slope of the bottom $4 \mathrm{~m}$ of the stems of the 71 Norway spruce trees (Fig. 8). The method appears to be relatively unbiased (slope parameter $=0.98$ ). However, there does appear to be a considerable amount of variation when the amount of lean is less than $2^{\circ}$. This may be due to the fact that the photographic method measured lean as the orientation of the stem centreline relative to the vertical axis, whereas the direct measurement used a plumb line attached to the outside of the stem and was therefore affected by stem taper.

The difference between the estimates of stem diameter from the photographic and direct caliper measurement was within $\pm 60 \mathrm{~mm}$ at the bottom part of the $4 \mathrm{~m}$ stem section and within $\pm 20 \mathrm{~mm}$ at the top (Fig. 9). In relative terms this difference 


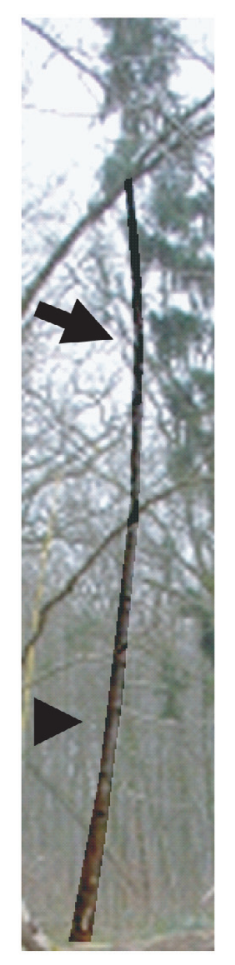

$\mathbf{Z}$

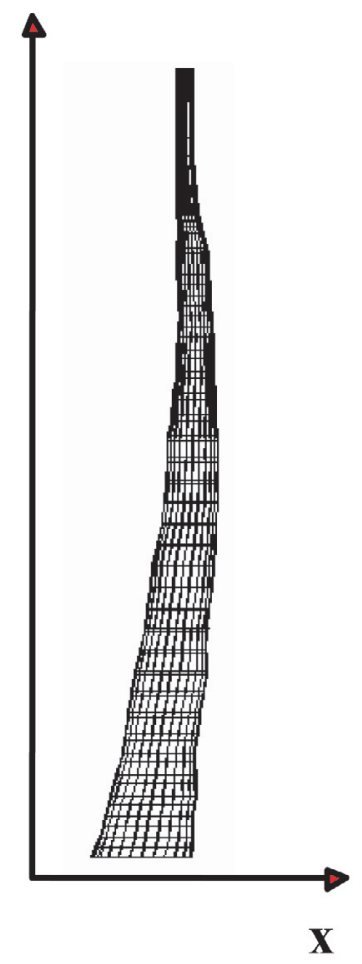

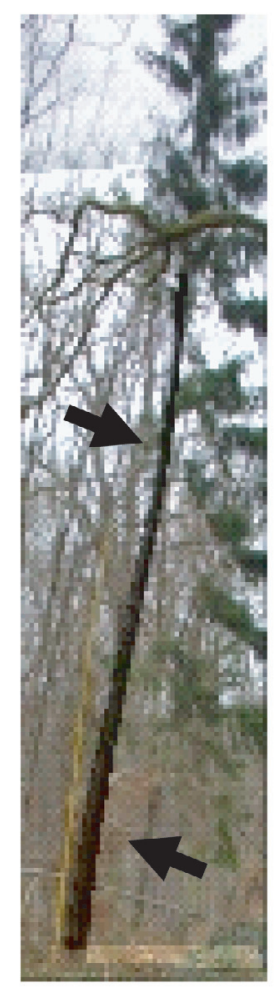

was approximately constant along the $4 \mathrm{~m}$ section and was within $\pm 15 \%$. The larger absolute differences between the estimates of stem diameter at the bottom of the tree are possibly due to the greater degree of ovality in this region. Because the orientation of the caliper measurements and the photographic measurements did not necessarily coincide, there may be considerable differences between methods for the two orthogonal diameters.

\section{CONCLUSIONS}

For the range of stand densities and tree sizes examined, the photographic method can be applied successfully. While we did not test the method in younger and denser stands where the live crown height was lower, we believe that the method could still be successfully applied in these stands. The method is only applicable to the branch-free section (or at least the section of the stem free of live branches), but even in relatively young stands the height of the green crown should be at least $50 \%$ of total tree height. In younger and denser stands, tree height will also be less and therefore the total height of the stem we wish to photograph will also likely be less. Therefore, the camera can be located closer to the target tree which will minimise visual obstructions from other trees.

Overall, the photographic method described in this article was found to be a fast (i.e., $10 \mathrm{~min}$ per tree to take the
Figure 5. Photographic method estimates of the local slope $(\varepsilon)$ and local slope orientation $(\beta)$ for the 70-year-old Norway spruce tree as a function of height up the stem. 

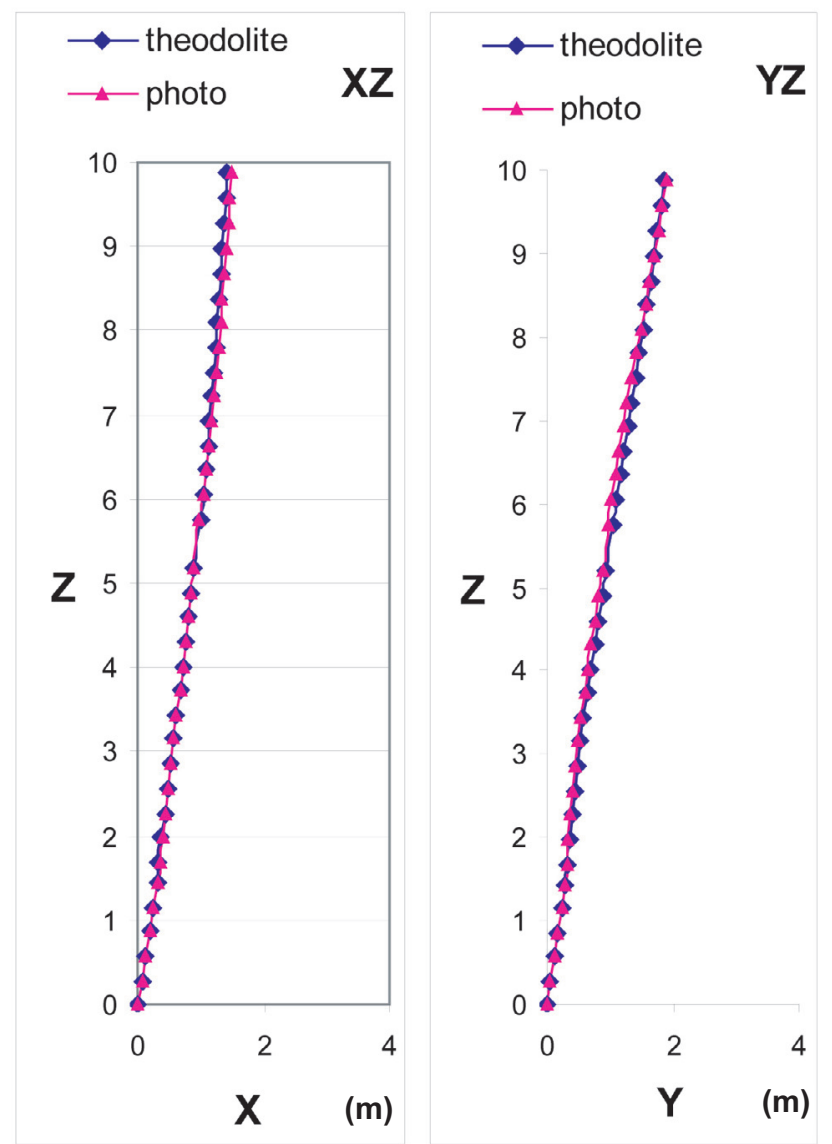

Figure 6. Projection of the profile of the tree on two planes (YZ and XZ) obtained by photographic and laser method. (all dimensions are in m).

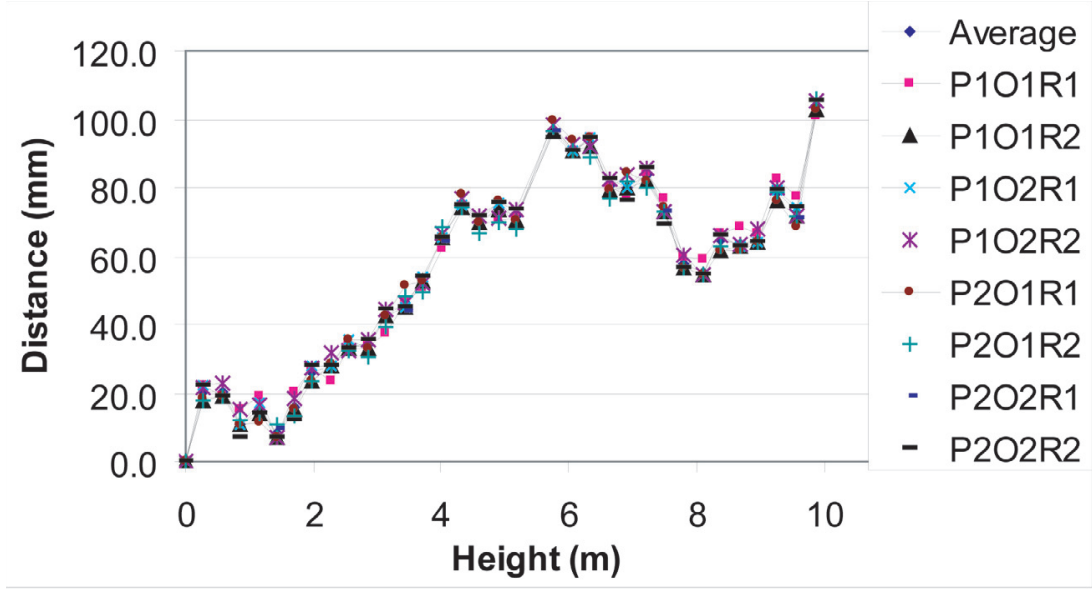

Figure 7. Difference between the eight profiles estimated by photographic and laser method as a function of the height in the tree (on the legend $\mathrm{P}$ - photo, $\mathrm{O}$ - operator, $\mathrm{R}$ - repetition). 


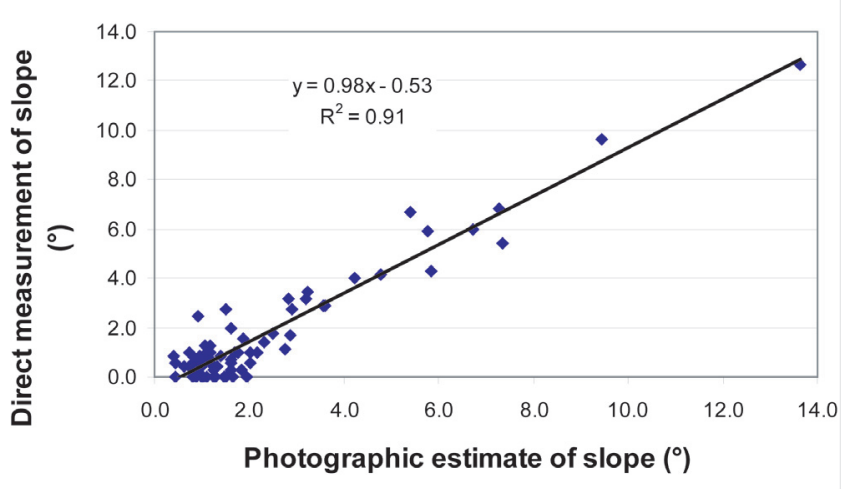

Figure 8. Comparison the slope of the bottom $4 \mathrm{~m}$ of the stem of 71 Norway spruce trees assessed by direct measurement and the photographic method.

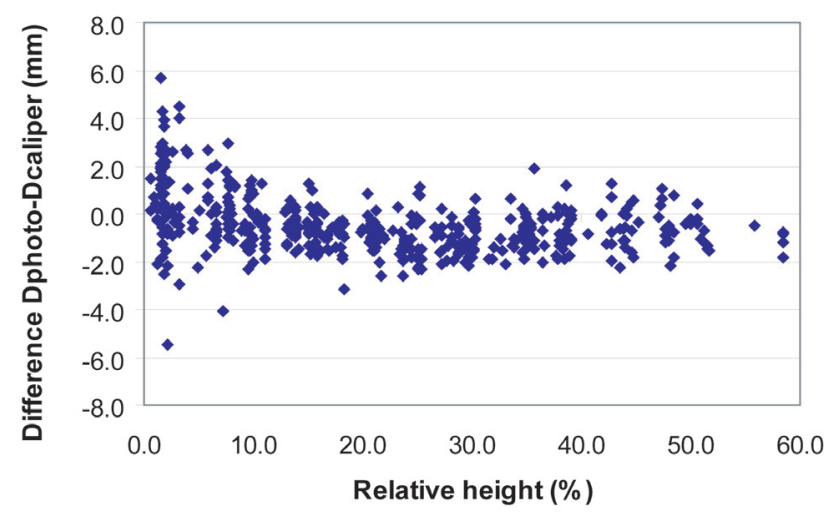

Figure 9. Difference between stem diameters estimated by the photographic method and direct caliper measurement as a function of relative height along the stem for the 71 Norway spruce trees.

photographs and 20 min to analyse) and repeatable means of providing a non-destructive estimate of the $3 \mathrm{D}$ profile for a large number of trees in the forest. High resolution digital photographs are able to give fine details of the stem of trees, without the need for special illumination conditions. This method can be used in inaccessible forests, with a high density of trees where other techniques may be problematic. The main limiting factors for this method are the wind and the need for visual access to the stem. Stem movement due to wind loading makes it difficult to take two orthogonal photographs in which the tree is in the same position. Visual access to the stem can also limit the height up the stem for which profiles can be calculated.

In the future, it is planned to improve the method by developing a system to automatically identify and calculate the tree profile from the photographs. This would reduce the processing time from the current level of $20 \mathrm{~min}$ per tree to something in the order of one minute per tree, thus enabling the method to become more efficient and potentially usable in routine forest inventory. With improvements in digital camera technology, pixel size is reducing. Therefore, the scaling factors will decrease as the number of pixels in the image increases. This will allow the precision of the photographic method to improve which will enable the identification of smaller features such as branches and defects, both of which have a significant effect on $\log$ quality.

Acknowledgements: Funding for this study was provided by the EU-project "Compression wood in conifers". Dr John Moore (Centre for Timber Engineering, Edinburgh) and two anonymous reviewers provided helpful comments on an earlier version of the manuscript.

\section{REFERENCES}

[1] Clark N., An assessment of the utility of a non-metric digital camera for measuring standing trees, Virginia Polytechnic Institute and State University, MS thesis, 1998, 119 p.

[2] Clark N., Zarnoch S.J., Clark A., Reams G.A., Comparison of standing volume estimates using optical dendrometers, Proceedings of the first international precision forestry cooperative symposium, Seattle, Washington, 2001, pp. 123-128.

[3] Constant T., Mothe F., Badia M., Saint-Andre L., How to relate the standing tree shape to internal wood characteristics: proposal of an experimental method applied to poplar trees, Ann. For. Sci. 60 (2003) 371-378.

[4] Crosby P., Barrett J.P., Bocko R., Photo estimates of upper stem diameters, J. For. 81 (1983) 795-797.

[5] Fürst C., Nepveu G., Assessment of the assortment potential of the growing stock - a photogrammetry based approach for an automatized grading of sample trees, Ann. For. Sci. 63 (2006) 951-960.

[6] Gaffrey D., Sloboda B., Fabrika M., Šmelko Š., Terrestrial single image photogrammetry for measuring standing trees, as applied in the Dobroc virgin forest, J. For. Sci. 47 (2001) 75-87.

[7] Gardiner B., Macdonald E. (Eds.), Compression wood in conifers the characterisation of its formation and its relevance to timber quality, Final report on the EU Compression Wood Programme QLKCT-2001-00177, 2005, 379 p.

[8] Hapca A.I., Distribution du bois de compression dans l'arbre en relation avec sa forme externe. Application à l'Epicéa commun (Picea abies Karst.), Ph.D. in wood science ENGREF Nancy, Équipe de Recherches sur la Qualité des bois, INRA-CRF, NancyChampenoux, France, septembre 2004, 200 p.

[9] Lundgren C., Predicting log type and knot size using external log shape data from a 3D log scanner, Scand. J. For. Res. 15 (2000) $119-126$.

[10] Nosenzo A., Applicatione di una tecnica fotografica per la misura dei diametric di pliante in piedi, Cellulosa e Carta 44 (1993) 20-25.

[11] Prodan M., Holzmeblehre, Frankfurt a. M., J.D. Sauerlander's Verlag, 1965, 664 p.

[12] Radi M., Castera P., Qualification de la forme de deux pins maritimes en liaison avec la structure de leur bois, Ann. Sci. For. 49 (1992) 185-200.

[13] Shelbourne C.J.A., Namkoong G., Photogrammetric technique for measuring bole straightness. Proceedings of the eight southern conference on forest tree improvement, June 16-17, Savannah, Georgia, 1966, pp. 131-136.

[14] Thomas R., Analyse des formes de troncs par photogrammétrie pour caractériser la qualité des bois. Application au pin sylvestre de Lozère. Ph.D. in wood science ENGREF Montpelier, mars 2000, $193 \mathrm{p}$.

[15] Weber J., Holtzmassenermittlung am stehenden Stamm auf grund photographischer Aufnahmen, Ph.D. thesis, Gieben, 1902. 